\title{
Comparison of the Microstructure of Machined and Laser Sintered Shaped Charge Liner in the Hydrodynamic Regime
}

\author{
H. O. Agu $^{1}$ (D) A. Hameed ${ }^{1} \cdot$ G. J. Appleby-Thomas ${ }^{1}$
}

Received: 20 April 2019 / Accepted: 18 July 2019 / Published online: 30 July 2019

(c) The Author(s) 2019

\begin{abstract}
To gain further insight into the mechanisms underlying jet formation and elongation of laser sintered shaped charge liners under high strain rate deformation, $\mathrm{Cu}-\mathrm{Cr}-\mathrm{Zr}$ alloy liners fabricated by selective laser sintering process were deformed by explosive detonation. Their as-manufactured (liner) and resultant (slug) microstructure have been investigated in comparison with those of traditional machined liners employing both optical and scanning electron microscopy. The resultant slug microstructure of both machined and laser sintered liners revealed a smaller refined equiaxed grain size consistent with traditionally fabricated liners, characteristic of dynamic recrystallization. The disappearance of the (originally present) pores in the post-shot/recovered material microstructure was observed for laser-sintered liners. Comparison of the forward and rear region of the slug revealed variations in liner deformation, a result attributed to temperature variation across the slug. In contrast with the machined liner, a unique feature of precipitation, observed in the ending (slug) microstructure of the laser sintered liner is indicative of the associated extreme high strain and strain rate liner deformation which occurred during slug formation. The precipitates are likely compounds of Chromium and Zirconium which are constituents of the laser sintered copper alloy-the first time this observation is reported. This study provides a link between post charge evolution microstructure and liner manufacturing processes, potentially providing a new route to help optimise jet formation and effectiveness.
\end{abstract}

Keywords Liner $\cdot$ Laser sintering process $\cdot$ Shaped charge $\cdot$ Copper $\cdot$ Microstructure $\cdot$ Temperature

\section{Introduction}

It has become widely accepted that shaped charge liners undergo dynamic recrystallization during liner collapse and jet formation to produce refined microstructures [1-3]. Under high strain/strain rate conditions, severe plastic deformation of the liner gives rise to nucleation and growth of new grains by continuous accumulation of dislocations [4]. During this process, low angle boundaries are being transformed into high angle boundaries accompanied by subdivision of original grains into small, sometimes equiaxed grains with significant microstructural refinement [5]. Although the resultant microstructure is controlled by the degree of deformation [1], it is influenced majorly by the strain/strain rate as well as the deformation temperature (itself a function of the nature of load on the liner) which varies along the jet

$\triangle$ H. O. Agu

henry.agu@cranfield.ac.uk

1 Centre for Defence Engineering, Cranfield University, Defence Academy of the UK, Shrivenham SN6 8LA, UK length [5, 6]. This variation, result in segments of the ending (slug) microstructure having higher deformation with apparently more refined microstructure than others [7]. Guo et al. observed that, in spite of the small equiaxed microstructure observed in recovered Tungsten slugs, significant variations in grain size were recorded at the centre, 0.5 and $1 \mathrm{~mm}$ away [7]. In short, the grain size of the slug appeared to change linearly outward with the smallest grains at the centre and the largest in the outer regions. A similar observation was reported by Murr et al., [2], where different grain sizes were observed at three concentric rings with the middle ring having the largest. Usefully, analysis of hydrocode simulations of a stretching shaped charge jet has revealed higher temperatures [6] and strain at the centre indicative of a higher degree of deformation. A relationship between the starting liner grain size $\left(D_{0}\right)$ and the ending grain size $\left(D_{s}\right)$, revealed that smaller starting liner grain sizes produce correspondingly smaller grain size ratios [1] because lower starting grain sizes are associated with dramatically higher levels of liner volumetric stored energy [8]. This implies that the 
ending grain size is influenced not only by the starting grain size but by the degree of deformation.

In addition to the starting liner microstructure, other factors such as the liner material properties, particularly; thermal conductivity and heat capacity as well as processing route have been reported to have a significant influence on the ending microstructure [7]. As an example, Murr et al., [9] observed that the grain size ratio between the starting and ending microstructure of Tantalum differs widely from that of Copper (by a ratio of 10:1.5), something the authors attributed to inherent liner material properties. In a separate study, comparing differences in processing technique, it was observed that equiaxed and well-annealed Tantalum both showed similar slug microstructural features which were consistent with a forged Tantalum liner, but with variations in average grain size. While the forged liner showed a resultant grain size of $35 \mu \mathrm{m}$, the equiaxed and well-annealed liner averaged $5 \mu \mathrm{m}$. With regards to the effects of processing routes, similar microstructural differences have been reported for several processing techniques [10]. A case in point is the difference observed between OFE copper and electrolytic tough pitched copper (ETP). In contrast to OFE copper, the ETP copper showed significant voids [11], suggesting an effect of processing technique on the ending (slug) microstructure. Surprisingly, while several liner processing techniques has been examined [10], liners fabricated by selective laser sintered (SLS) process have yet to be considered. This study consequently deals with the characterization and analysis of slug recovered from explosively deformed laser sintered liner. In the present work, liners fabricated by both conventional machining and the selective laser sintering process were deformed by explosive loading to form jet and slug. We examined the microstructures of the liners and resultant slugs in comparison with machined OFC copper liner employing both optical and scanning electron microscope (SEM).

\section{Experimental Method}

Oxygen free copper (OFC) and $\mathrm{CuCrZr}$ alloy of grade C18150 were employed for the production of the machined and laser sintered liners respectively. The chemical composition of CuCrZr alloy of grade C18150 employed is detailed at Table 1.

Table 1 The chemical composition of $\mathrm{CuCrZr}$ grade $\mathrm{C} 18150$

\begin{tabular}{ll}
\hline Element & Content $(\%)$ \\
\hline Copper $(\mathrm{Cu})$ & $98.12-99.27$ \\
Chromium $(\mathrm{Cr})$ & $0.5-1.2$ \\
Zirconium $(\mathrm{Zr})$ & $0.03-0.3$ \\
\hline
\end{tabular}

The liners design used was of 50-mm charge diameter and $1.5 \mathrm{~mm}$ liner wall thickness and was inclined at $42^{\circ}$ (cone angle). The sintered liner was solution annealed at $960{ }^{\circ} \mathrm{C}$ for $3 \mathrm{~h}$, water quenched and heat treated at $460{ }^{\circ} \mathrm{C}$ for $3 \mathrm{~h}$, while the machined liners were used as produced. Figure 1 shows images of the produced liners. The liners were deformed in the plastic and hydrodynamic regimes upon detonation with Plastic Explosive Number 8 (PE8). The jet tip velocity produced by the machined liner was determined independently using AUTODYN 2D hydrocode to be $8.6 \mathrm{~km} / \mathrm{s}$. The jet was allowed to penetrate a mild steel target placed 3 charge diameters away. After firing, the resultant slugs were recovered, sectioned transversely to the slug axis, prepared and observed optically and in scanning electron microscope (SEM). Metallographic preparation involved successively finer (320 grit and then 800 grit) silicon carbide grinding followed by rough polishing using 3-micron diamond suspension and then a final polish using an alumina suspension. Ammonium hydroxide/hydrogen peroxide etch was then employed before both optical and SEM analysis (using an Olympus BX53M optical and Scanning Electron Microscope, Hitachi type SU3500 respectively).

For grain size measurement, three standard ASTM approaches were considered. These were: a comparison procedure which involved a direct comparison of the grain structure to a series of the graded image superimposed over the microstructure; the planimetric (or Jeffries) procedure which requires actual counting of the number of grains within a known area and the Intercept procedure. These approaches have been summarized in Ref. [12]. Of the three approaches, the intercept procedure which is faster and more convenient than the planimetric method was employed to determine the grain sizes of the starting (liners) and ending microstructure. Further, the intercept method has demonstrated reliability and efficiency for the determination of grain size and is particularly recommended for grains that depart from uniform equiaxed form [12]. The Heyn Lineal Intercept procedure backed by Image J software which
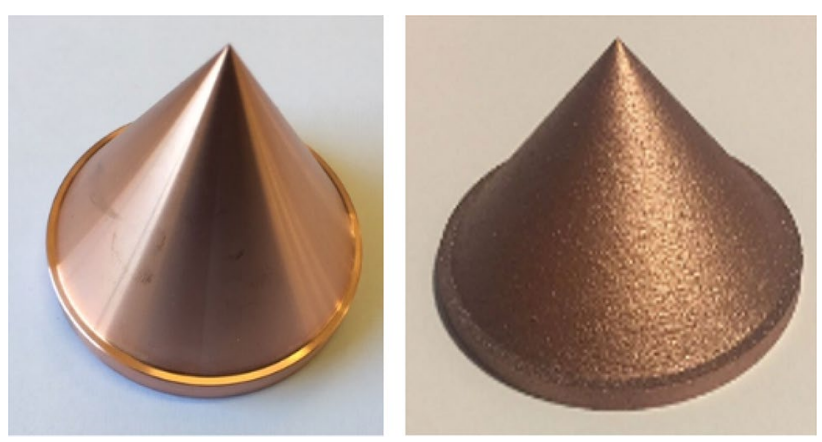

Fig. 1 Images of machined OFC liners (left) and Laser sintered liner (right) in their as-produced state 
employs long straight lines was used. To ensure precision, counting was done on three long lines with low magnification from which the average was taken.

\section{Results and Discussion}

Figure 2 shows optical micrographs of the machined and laser sintered copper liner before deformation. The microstructure of the laser sintered liner (Fig. 3b) consists of elongated grains along the build direction. The density of the machined liner was measured using an XS 105 dual range analytical balance from Mettler Toledo as $8.91 \pm 0.02 \mathrm{~g} / \mathrm{cm}^{3}$ while the laser sintered liner was found to be $8.77 \pm 0.02 \mathrm{~g} /$ $\mathrm{cm}^{3}$, comprising approximately $98-99 \%$ copper with $1-2 \%$ Chromium and Zirconium. The average measured grain size of the machined liner was $\sim 54 \mu \mathrm{m} \pm 4 \mu \mathrm{m}$ while the laser sintered liner after being solution annealed at $960{ }^{\circ} \mathrm{C}$ for $3 \mathrm{~h}$, water quenched and heat treated at $460{ }^{\circ} \mathrm{C}$ for $3 \mathrm{~h}$, exhibited elongated grain sizes ranging from circa 20 and $70 \mu \mathrm{m} \pm 6 \mu \mathrm{m}$ along the horizontal and vertical axis respectively; an indication of a partially recrystallized structure arising from the sintering and post-production processes on the fabricated part. Essentially, fusion heat caused in situ recrystallization during the building process [13], resulting in partial recrystallization of the microstructure. Of particular significance is the presence of pores which is one of the common defects in SLS liners [14] and which are observable in the SEM image in Fig. 3. The pore sizes and shapes are irregular with no distinct pattern. In addition, there are characteristic lines running diagonally which likely correspond to the layer boundaries in areas of their fusion during sintering ('scan tracks'); this supposition is backed by their separation which nominally correspond to the laser sintered machine manufacturing tolerance of separation of ca. $100 \mathrm{~mm}$ per-sweep. However, it is not known

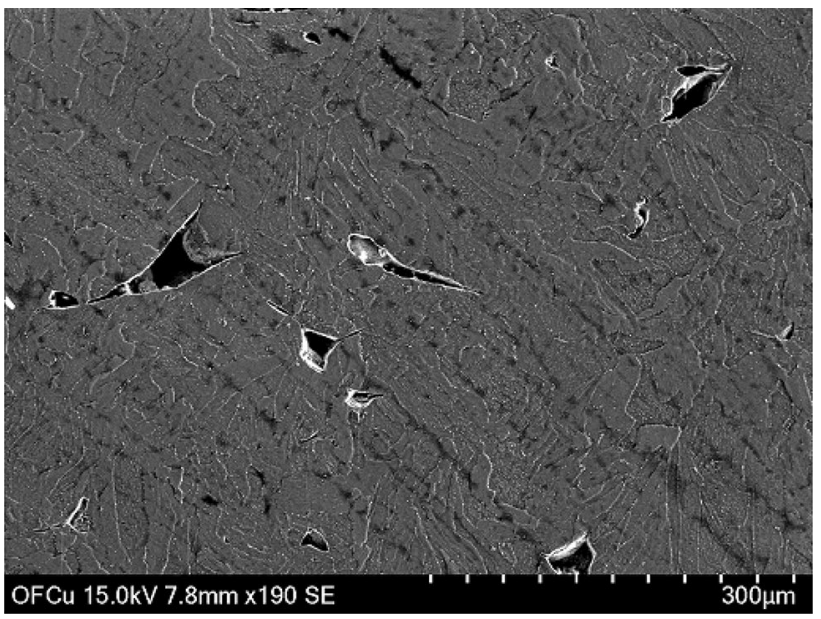

Fig. 3 SEM observation of the laser sintered liner microstructure revealing scan tracks and irregularly shaped pores before deformation

whether the grain structure or chemical composition along the track would differ from other regions. Further work may be required in this regard to ascertain this.

\section{Optical Metallography of Slug Recovered from the Machined Copper Liner}

It is pertinent to note that unlike the soft recovery process where the jet/slug is recovered in flight, interaction between the jet and mild steel plate could increase the strain and generate higher deformation temperature in the jet/slug, leading to higher grain refinement. Figure 4 shows optical metallographic observations of both the starting and ending microstructures of the machined copper liner and recovered slug for comparison. It is very convincing that there is a significant reduction in the grain size of the recovered slug compared to the starting liner material. The measured
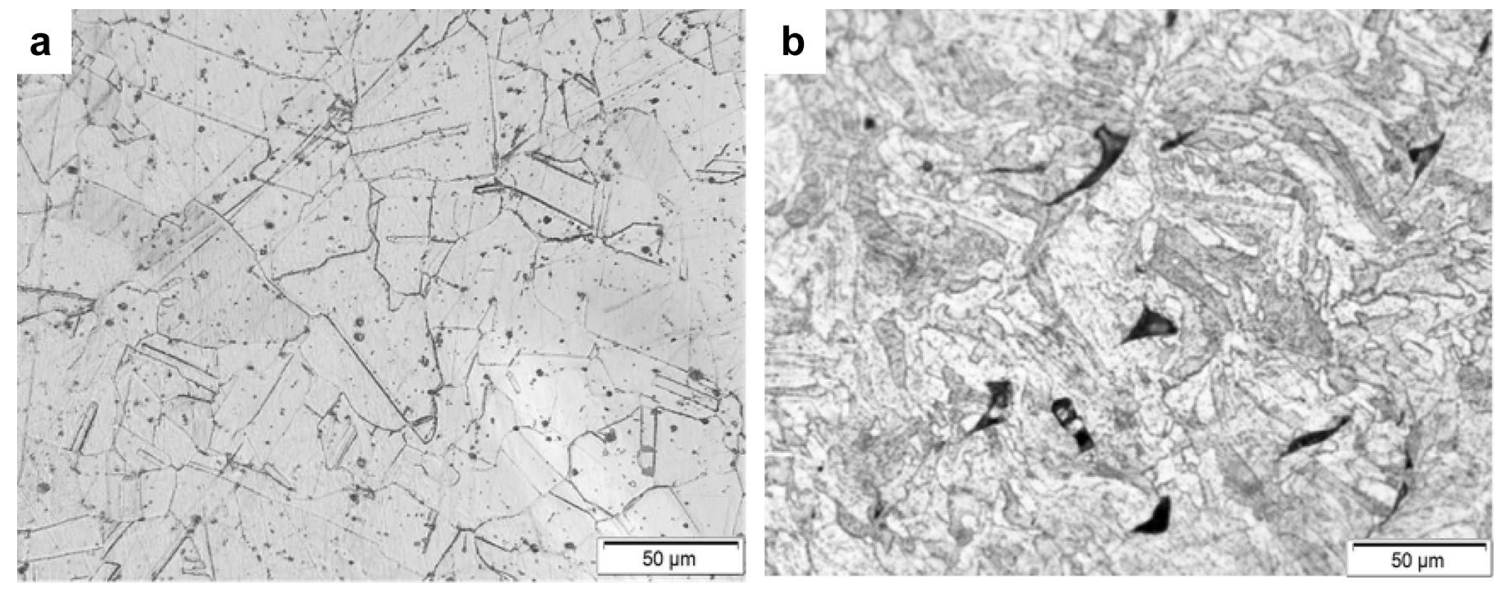

Fig. 2 Optical Images of the starting microstructure of a machined OFC Copper liner and $\mathbf{b}$ laser sintered Copper liner $(\times 20$ respectively) 

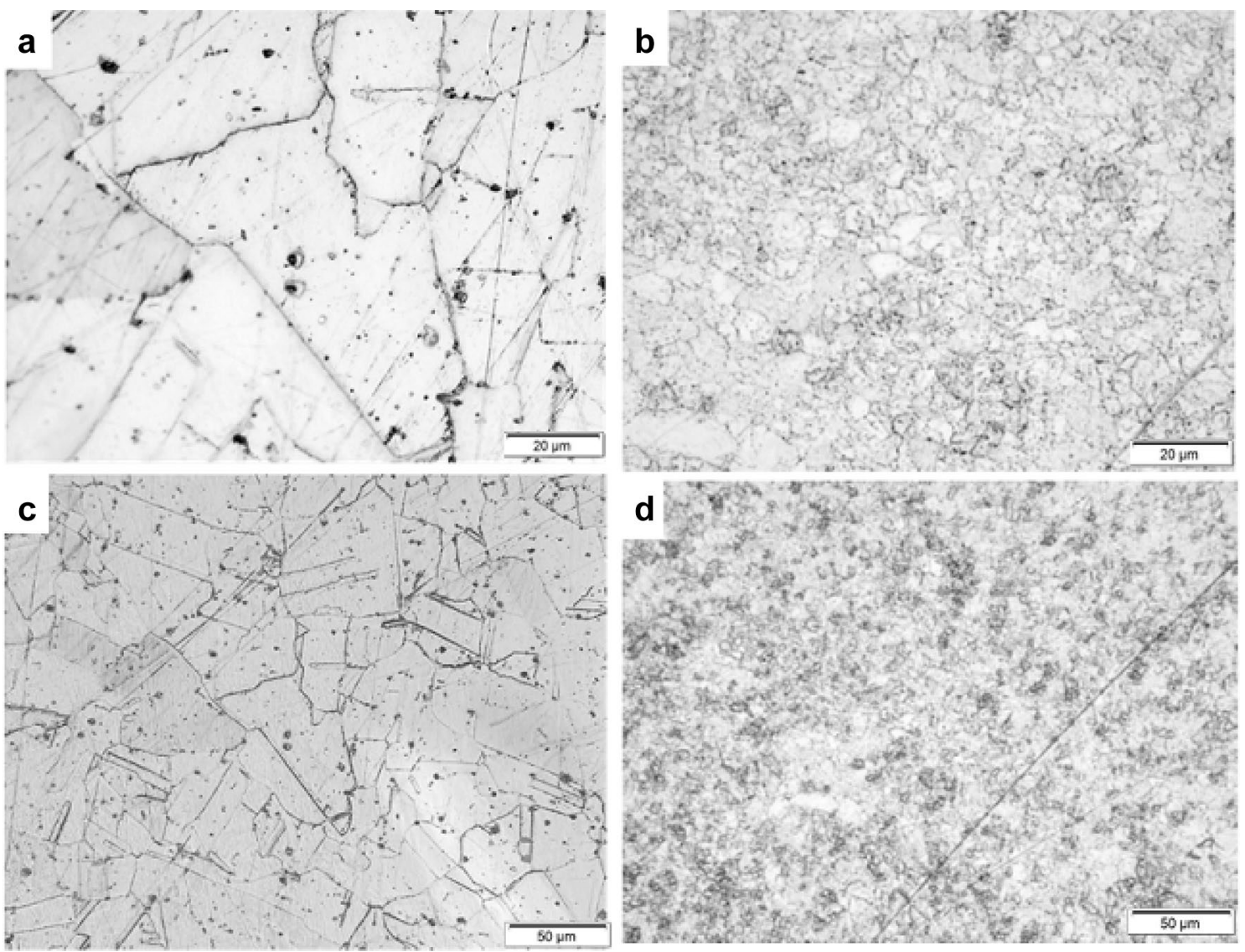

Fig. 4 Comparison of the initial and final microstructure of machined copper liner and slug; a The microstructure of starting copper liner $\times 50$. b The microstructure of recovered copper slug revealing equi-

grain size of the recovered slug averaged $6 \mu \mathrm{m} \pm 2 \mu \mathrm{m}$ This phenomenon (grain size reduction/refinement) has been reported extensively elsewhere $[1,8]$, consistent with the concept of dynamic recrystallization occurring at such high strain rates. In fact, Murr et al., observed a reduction in grain size by a factor of 10 for copper shaped charge liners. In this study, the measured recovered material grain sizes were equiaxed, consistent with previous work $[2,15]$ and varies from the initial liner grain size (an average of $54 \mu \mathrm{m}$ ) by a factor of 9. A similar study on Tungsten shaped charges liners revealed the role of dislocations in the refinement of the microstructure during dynamic recrystallization suggesting a link between strain and grain size of the recovered slug [7].

We have also observed variations in grain size refinement in various sections of the recovered slug. As an example, the forward (tip region) and the rear sections of the recovered slug detailed in Fig. 5 shows some variation in the grain sizes. Although slightly, it is apparent that there is a more refined microstructure with smaller grain sizes in the rear (Fig. 5a) of typical average grain size of $4 \pm 2 \mu \mathrm{m}$ than in the forward section (Fig. 5b) where a typical average grain size of $7 \pm 2 \mu \mathrm{m}$ is apparent (please note that no particular

axed microstructure and reduction in grain size $\times 50$. c The microstructure of starting liner $\times 20$. d Recovered copper slug x20

attention was placed on the distance/depth from the centre axis at which the samples were extracted from both positions). This provides further proof of the variation in the degree of deformation in the microstructure across the resultant slug. This observed apparent variation in the grain size refinement at different sections of the slug has been reported severally elsewhere $[2,9,16]$. However, in all the recovered slug sections for the machined copper liner, no melt-related phenomenon was observed on the samples analysed-strongly suggesting hydrodynamic behaviour (flow, rather than melt).

\section{Optical Metallography of Slug Recovered from Laser Sintered Liner}

Figure 6 shows an image of the recovered laser sintered slug while Fig. 7 shows optical metallographic observations of the starting and ending microstructures of the laser sintered copper liner and slug for comparison. In contrast with the elongated grains observed along the build direction of the starting liner microstructure, the recovered slug shows a more refined/microstructure with a reduction in the 

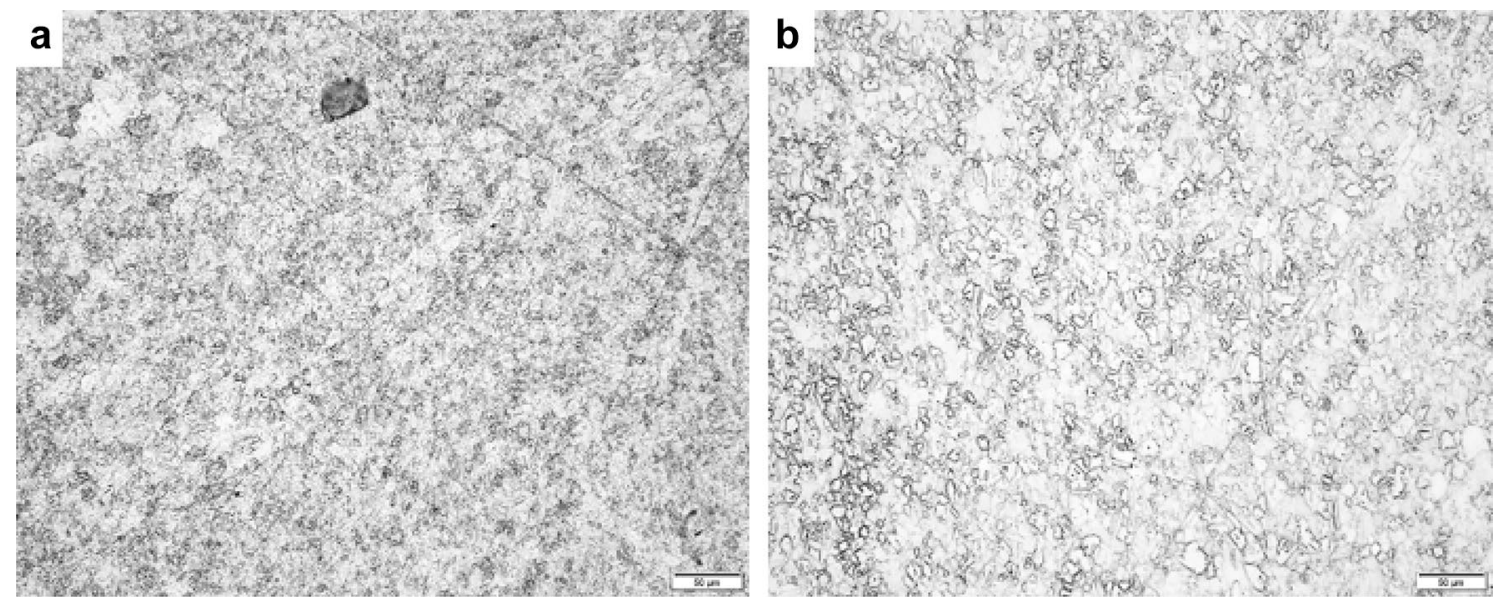

Fig. 5 Optical micrograph of slug recovered from the machined copper liner experiment. a The rear region $(\times 20)$. b The forward region $(\times 20)$

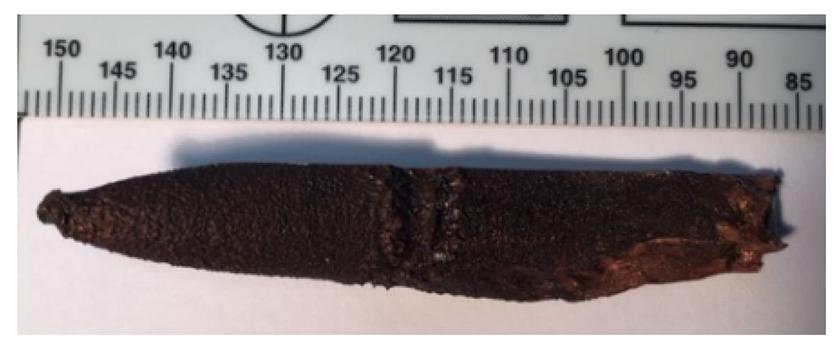

Fig. 6 Recovered laser sintered slug (mm)

average grain size from $20 \pm 3 \mu \mathrm{m}$ in the vertical direction to an average grain size of $\sim 14 \mu \mathrm{m}$. As the final grain size is dependent on the initial grain size, the low reduction in variation between the initial and ending microstructures is attributed to the already reduced starting grain size resulting from the post-processing of the sintered liner part. More importantly, the pores which were observed in the starting liner are completely absent in the slug. While it is difficult to rule out any form of melting or melt-related phenomenon as reported in previous shaped charges studies [5], several precipitates, distributed randomly in the microstructure were visible and concentrated along the grain boundaries. A similar observation has been reported in Ref. [13] of a sintered $\mathrm{CuCrZr}$ alloy during high-temperature annealing. $\mathrm{X}$-ray diffraction analysis of the precipitate revealed a high content of $\mathrm{Cr}$ and $\mathrm{Zr}$ with dimensions ranging from the $\mathrm{nm}$ to $\mu \mathrm{m}$ scale without forming any intermetallic compounds. While $\mathrm{Cu}_{8} \mathrm{Zr}_{3}$ precipitates were formed at higher temperatures, in contrast with $\mathrm{Cu}_{10} \mathrm{Zr}_{7}$, the variation in behaviour of the precipitates suggests the influence of temperature and annealing condition on the precipitation pattern. As a consequence, the apparent high temperature encountered during the jet formation process is a possible cause of the precipitation observed in this study. Whether the precipitate is a result of melt or melt related phenomenon is a subject of discourse. However, it is pertinent to point that, no melt or melt-related phenomenon has been reported in previous shaped charge studies [7] except for electroformed nanosized nickel liners where melting was observed due to the high volumetric stored energy associated with small grains [8]. Hence, even though the liner flows hydrodynamically ('as fluid') under impact loading, it remains solid because the liner is not heated to its melting temperature [17]. In fact, at such extremely high strain/strain rate the liner deforms plastically and is drawn in the form of a wire with diameter much lower than the initial diameter. Under such conditions, it is very likely that the precipitates of Chromium and Zinc are evolved as Chromium is not soluble in Copper. Previous work on the heat treatment of $\mathrm{CuCrZr}$ at $450{ }^{\circ} \mathrm{C}$ indicates a high content of $\mathrm{Cr}$ and $\mathrm{Zr}$ located at the melt pool boundaries [13], something similar to the slug microstructure observed here which indicates that the particles have formed during the solidification of the melt pool. As such, we speculate that the formation of precipitates in the slug is an indication of adiabatic temperature rise during liner collapse and jet formation. However, as this is only a speculation, further work may be required may be required to confirm the compound formed.

A particularly interesting phenomenon is the further grain size reduction and precipitates observed in the rear slug (Fig. 7c) in comparison with the forward section; similar behaviour observed in the ending microstructure of machined liners. Although the depth from which the samples were collected were not considered (in both liner processing techniques), it is only an indication of the degree of deformation in various sections of the slug.

A comparison of the final/ending microstructure of the machined and laser sintered liners in Fig. 8 revealed two different ending microstructures. Firstly, as mentioned 


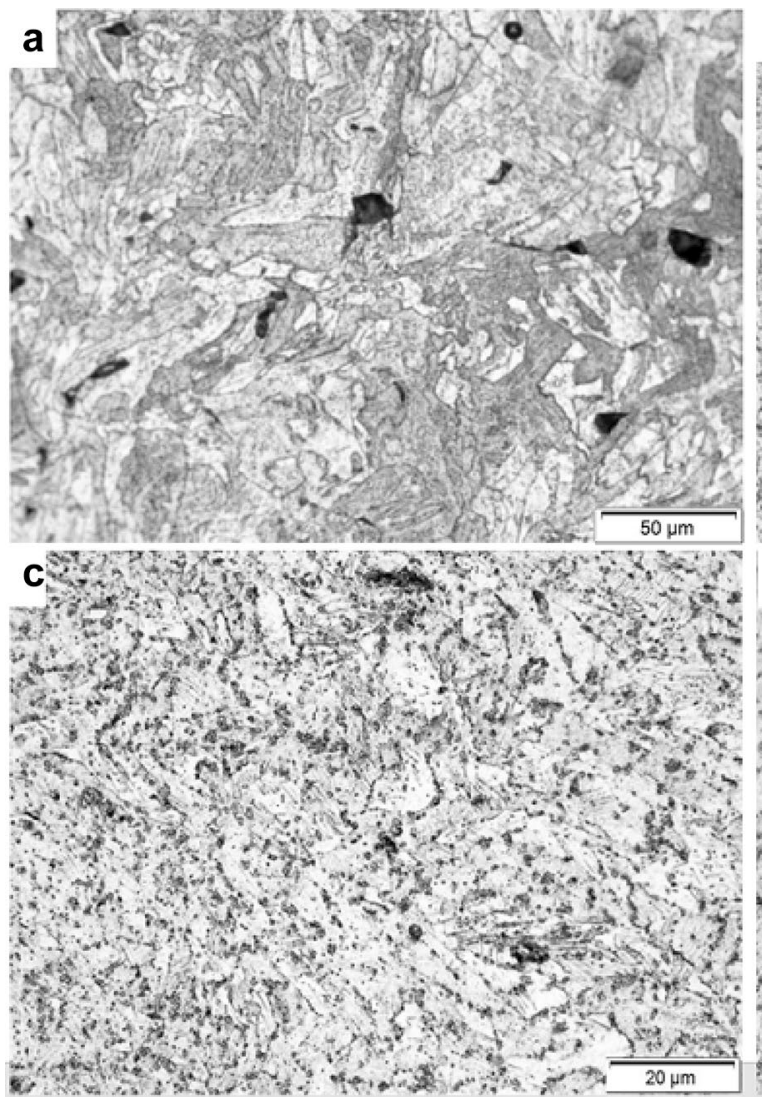

Fig. 7 Comparison of the initial and final microstructure of laser sintered copper liner and slug; a Starting laser sintered copper liner, b recovered slug, $\mathbf{c}$ forward region of recovered laser sintered copper

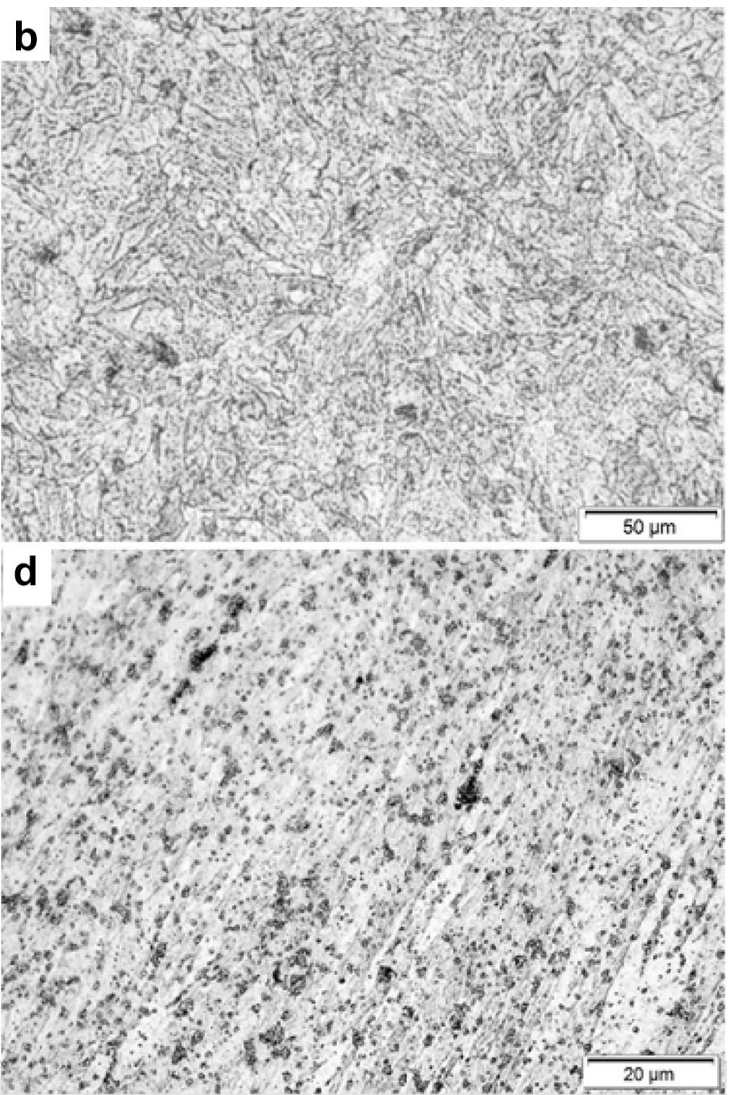

slug. d Rear region of recovered laser sintered slug showing several precipitates. Magnifications are the same
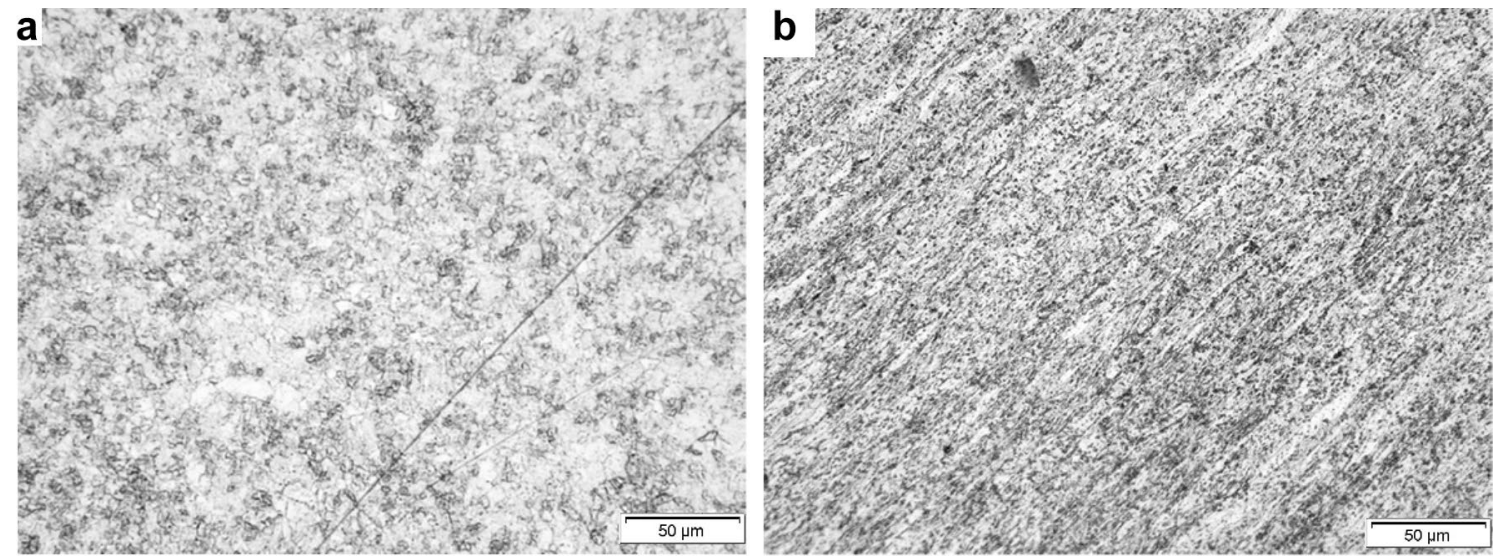

Fig. 8 Comparison of the ending microstructure of machined and laser sintered liner

earlier, while the machined liners showed an equiaxed grain size distribution, the microstructure of the resultant slug from the laser sintered liner showed the presence of precipitates distributed randomly. Although, the precipitates formed were not investigated in this study, previous work has shown that because of the low solubility of Chromium in Copper, the formation and growing of Chromium precipitates especially at grain boundaries (apparent in the recovered slug here) is triggered by high temperatures and exposure times [13] which suggest the 
effect of temperature on liner deformation evaluated in the subsequent section.

\section{Measurement of the Jet Temperature}

The first attempt to measure the temperature of a shaped charges jet was by Von Holle and Trimble [17]. Employing infrared radiometry technique, properties of $81.3 \mathrm{~mm}$ diameter copper shaped charge jet loaded with Comp. B or Octol were determined. An average recorded jet temperature of $428^{\circ} \mathrm{C}(701 \mathrm{~K})$ was measured for Comp. B, while $537^{\circ} \mathrm{C}$ $(810 \mathrm{~K})$ was recorded for Octol [18]. Subsequent measurement recorded by Lassila found an exterior jet temperature of $500{ }^{\circ} \mathrm{C}$ using CALE - an arbitrary Lagrange-Eulerian computer code [19]. Essentially, jet heating results from the interaction of the detonation waves with the liner (grazing detonation), plastic work during liner collapse, and jet elongation [19, 20]. In this study, an Autodyn 2D [21-23] numerical algorithm was used to study temperature variation in shaped charges. The use of Autodyn 2D to measure jet temperature was employed by Elshenawy et al., for a Zirconium shaped charge jet but was limited to the jet temperature for calculating the break-up time of Zirconium liners [6]. Here, the temperature at different sections of the jet was calculated to proffer a possible explanation to the variation in grain refinement in various sections of the jet. The hydrocode temperature calculations were first validated by modelling a BRL-81.3 mm shaped charge [24] in the multimaterial Eulerian grid, employing the complete Mie-Gruneisen form of the equation of state which describes the heat capacity variations and thermodynamic properties with a reference temperature of $300 \mathrm{~K}$ and heat capacity $3.83 \mathrm{e}-4 \mathrm{~J} /$ $\mathrm{Kg} \mathrm{K}$ [25]. We derived the temperature of the jet due to severe plastic work, during jet elongation (as this has been shown to produce higher temperature increase in the jet), rather than the grazing detonation wave (occurring during liner collapse) [20] for an $81.3 \mathrm{~mm}$ shaped charge. The longitudinal section of Autodyn 2D shaped charge layout is shown in Fig. 9.

The jet temperature was recorded at three different times: $36 \mu \mathrm{s}, 45 \mu \mathrm{s}$ and $54 \mu \mathrm{s}$ respectively during the jet elongation regime. From the resultant jet profiles in Fig. 10, it is apparent that temperature varies across the jet length with the highest temperature (up to $1500 \mathrm{~K}$ ) on the jet axis while the outer surface temperature ranges from $795 \mathrm{~K}\left(522{ }^{\circ} \mathrm{C}\right)$ to $905 \mathrm{~K}\left(632^{\circ} \mathrm{C}\right)$.

When the temperature and time are plotted in Fig. 11, it was observed that the jet temperature rises initially to a peak before equilibrating at a steady temperature of $710 \mathrm{~K}$ $\left(437^{\circ} \mathrm{C}\right)$. This recorded temperature agrees well with the temperature recorded by Von Holle and Trimble $(720 \mathrm{~K})$ [17]. The high temperature recorded on the jet central axis is likely a result of the high dynamic pressure at the collision point as the liners interact with each other. This extremely high-temperature phenomenon at the jet centre axis could account for the unique liner deformation patterns reported in the region around the jet axis. For instance, metallurgical examination by Lassila et al., [19] of soft recovered copper jet particles and slug indicate that a central region of approximately $10 \%$ of the jet's diameter was molten. Baoxiang et al. observed a wave pattern around the centre axis of the jet microstructure, characteristic of fluid instability which was speculated to cause jet break up [26]. More interestingly, the presence of a central hole at the jet centre axis [26] which was postulated to account for an unexplained $6.5 \%$ density deficit [27] in stretching shaped charge jets [26] was noted. Although these phenomena were attributed to high dynamic pressure (around $70 \mathrm{GPa}$ recorded at a distance less than $1 \mathrm{~mm}$ from the axis and decaying to an average of approximately $15 \mathrm{GPa}$ ), which tends to resist further compression

Material Location

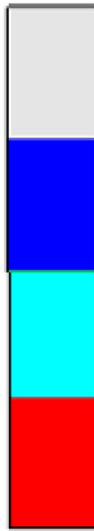

Void

ANSYS

R18.0

Academic

AL 2024

CU-OFHC

OCTOL

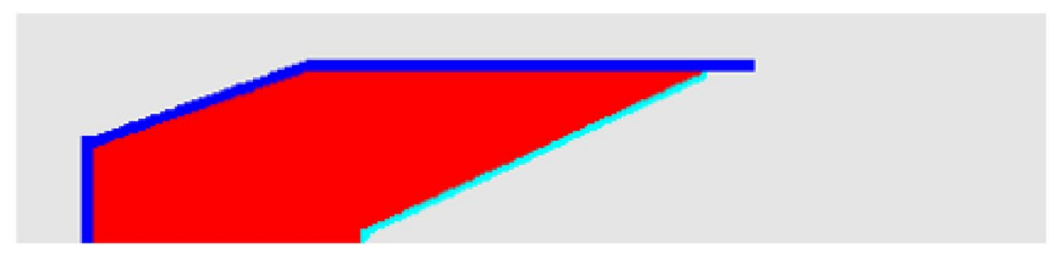

Fig. 9 Autodyn 2D Layout of an $81.3 \mathrm{~mm}$ charge diameter shaped charge in the multi-material Eulerian grid 
Fig. 10 Jet temperature for BRL $81.3 \mathrm{~mm}$ shaped charge at various times and before jet particulation
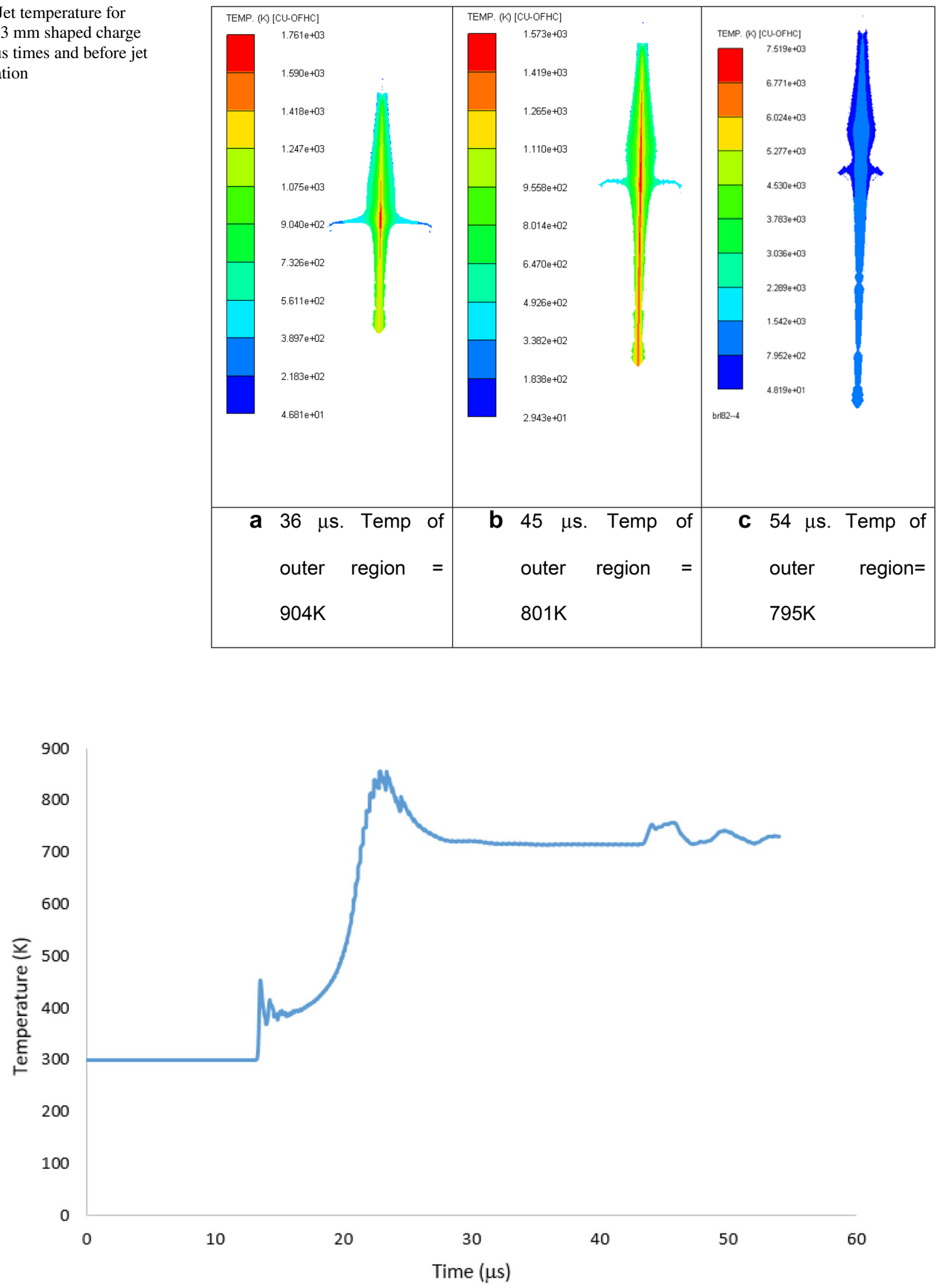

Fig. 11 Jet temperature variation with time recorded from Autodyn 2D simulation 
of the liner towards the centre axis and possibly altering the deformation pattern [26], from the findings reported here, giving the high temperature recorded at the jet central axis, it is likely that the material in the central region of the jet and slug experiences melting (lasting for only a short time-a few microseconds) as the temperature's recorded are higher than the melting temperature of Copper-something observed by Lassila [19] to account for the $10 \%$ melt phenomenon recorded in her work. If this is true, and under such molten state, it is speculated that, the forward action of the travelling molten jet would invariably cause a corresponding backward motion of the fluid, leaving a space (centre hole in the jet and slug).

To verify temperature distribution across the jet length, moving temperature gauges were placed at the outer, middle and inner surfaces of the liner represented in Fig. 13. It is generally known that for conventional conical charges, the first $30-40 \%$ of the liner from the theoretical apex forms the tip of the jet [28]. Employing a simple Lagrangian coordinate, postulated by Carleone and Chou [21] in Fig. 12, we identified suitable positions of various segments of the jet and on the liner where our gauges were placed [21]. The axial liner position is described by coordinate " $\mathrm{x}$ " whereas the position of the jet is given by coordinate $\xi$ in Eq. 1:

$\xi(x, t)=\mathrm{Z}(x)+\left(t-t_{o}\right) V_{j}(x)$

where $\mathrm{Z}(x)$ is the location of the formation, $t_{o}$ is the time at which the liner element first arrives at the axis, and $V_{j}(x)$ is the jet velocity, which is a function of the liner position and time. Accordingly, we measured the jet temperature at various positions of the jet including the outer surface, midradius and jet centre. The temperature across the jet length was also evaluated by placing temperature gauges on defined

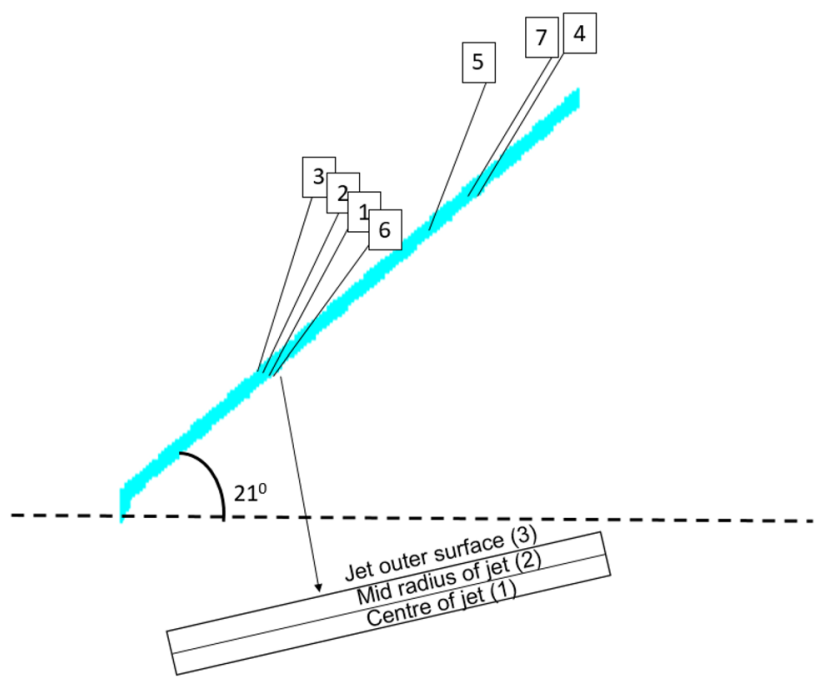

Fig. 13 The cross section of the liner showing gauge locations

areas on the liner as shown in Fig. 13 to obtain corresponding temperatures at the marked regions on the jet (Fig. 14).

From Fig. 15, it is apparent that the temperature across the jet width varies linearly outward. The highest temperature was recorded at the gauge trace closest to the inner centre axis $(1100 \mathrm{~K})$ and this was observed to decrease outward towards the surface, consistent with the jet profile (Fig. 9) suggesting that temperature decreases as the jet elongates. Hence the jet centre is heated higher than the outer surface providing evidence of temperature variation along the entire jet width with resultant variation in grain refinement.

To investigate how the temperature varies across the jet length, temperature gauges were placed at three different outer positions on the jet (gauges 4, 5 and 6, in Fig. 16). Adequate care was taken to ensure the gauges sat

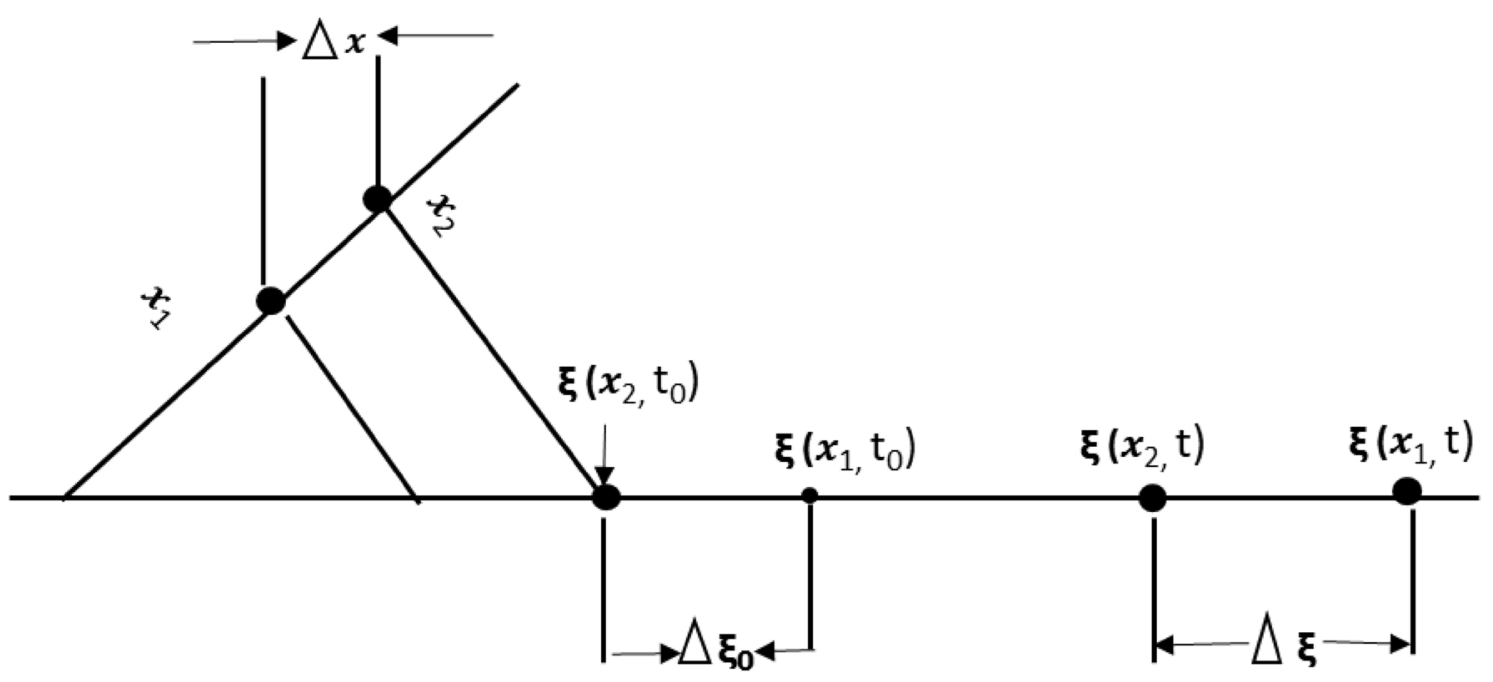

Fig. 12 Relationship between the liner coordinate $\times$ and the jet coordinate $\xi$ adapted from Ref. [28] 


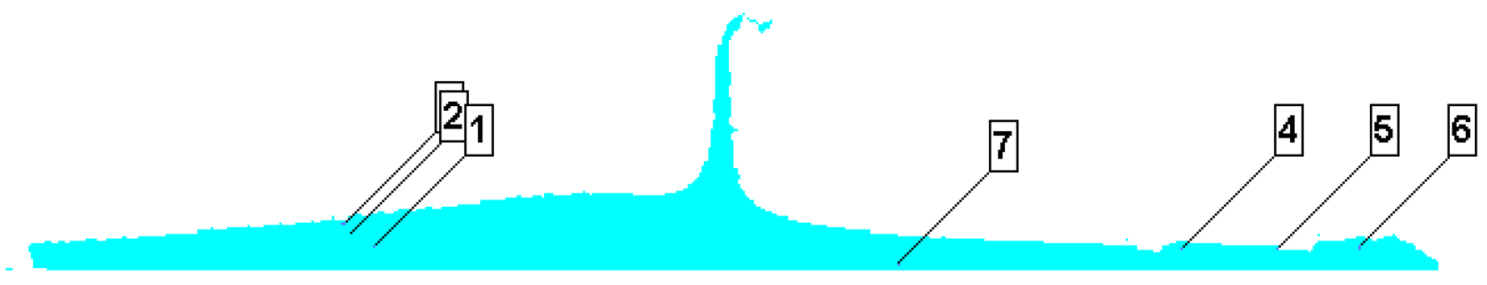

Fig. 14 Corresponding gauge locations on the shaped charge jet during formation and elongation

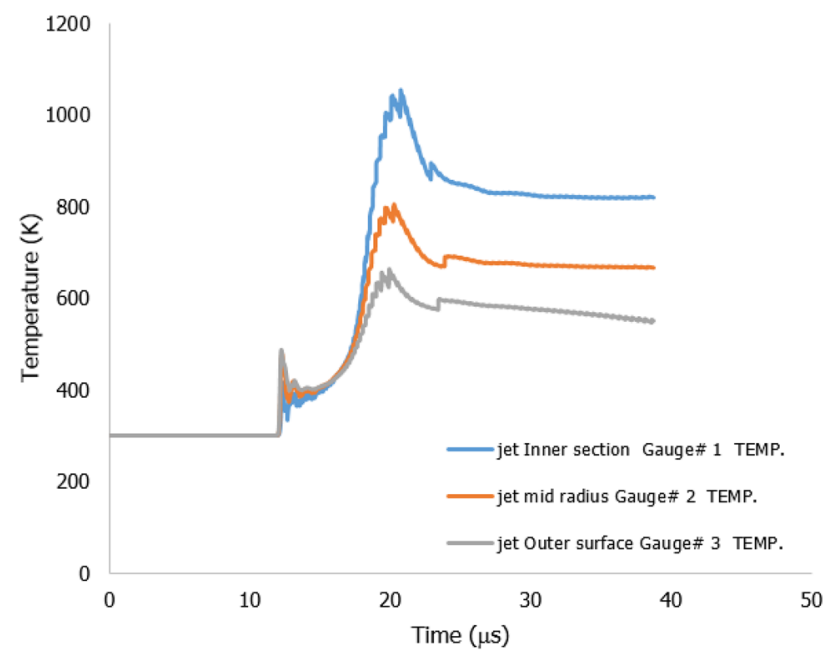

Fig. 15 The recorded temperature histories of tracers positioned at the outer middle and inner section of the liner

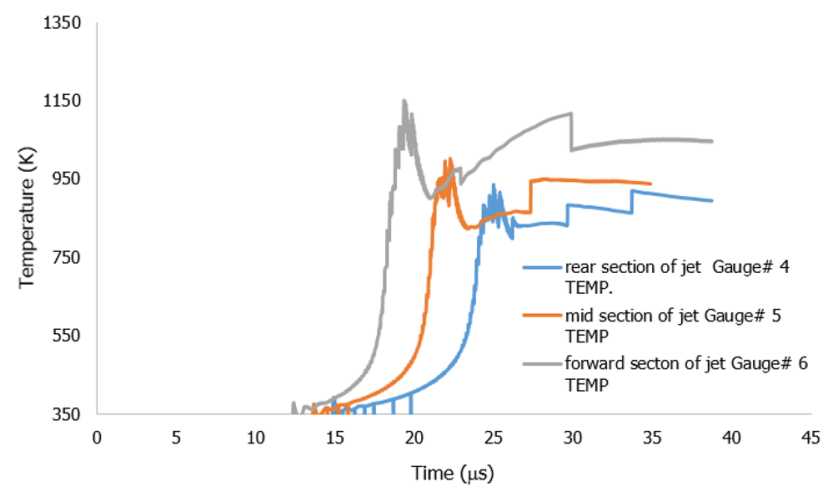

Fig. 16 The recorded temperature Histories at the forward, middle and rear sections of the jet

horizontally at the same depth on the outer surface. The highest temperature was found at the forward section of the jet and this decreases down to the rear as can be seen in Fig. 16; an indication of the temperature variation across the jet length. If this trend continues across the entire jet and slug length, it would therefore suggest that temperature across the outer surface of the jet length varies with the jet tip recording higher temperatures.

\section{Conclusion}

The starting microstructures for machined and laser sintered copper shaped charge liners have been compared with corresponding, recovered (ending) slugs-the first time the microstructure of recovered selective laser sintered slugs has been studied. It has been observed that:

a. Consistent with previous work [1, 2, 5, 9], a common feature of both processing techniques in terms of their end/post-employment microstructures is a reduction in grain size (slug), which is a classical feature of dynamic recrystallization.

b. Variation in grain refinement at different sections of the slug is an indication of differences in the degree of deformation attributed to temperature variation across the jet length and width.

c. According to jet temperature calculations, it has been shown that the jet central axis experiences a transient higher temperature exceeding the melting temperature of copper; this is speculated to account for the $10 \%$ melt reported by Lassila et al., [19], wave fluid like instability reported by Baoxiang et al., [26] and the observed hole in the centre of soft recovered jet.

d. The precipitates formed in the ending microstructure of recovered laser sintered slug are likely compounds of Chromium and Zirconium formed from an adiabatic temperature rise during liner deformation.

Acknowledgements Air Marshal Sadique Baba Abubakar is appreciated for sponsoring the $\mathrm{PhD}$ programme under which this project was carried out. The authors wish to thank Lt Col Liz Nelson for sponsoring the ATO study under which the shaped charge experiments were conducted. The authors would also like to acknowledge the support offered by the technical staff of the Schools' workshop in producing the shaped charge liners. 
Open Access This article is distributed under the terms of the Creative Commons Attribution 4.0 International License (http://creativeco mmons.org/licenses/by/4.0/), which permits unrestricted use, distribution, and reproduction in any medium, provided you give appropriate credit to the original author(s) and the source, provide a link to the Creative Commons license, and indicate if changes were made.

\section{References}

1. Murr LE et al (1995) Comparison of beginning and ending microstructures in metal shaped charges as a means to explore mechanisms for plastic deformation at high rates. J Mater Sci 30(11):2747-2758

2. Gurevitch AC et al (1993) Characterization and comparison of microstructures in the shaped-charge regime: copper and tantalum. Mater Charact 30(3):201-216

3. Murr LE, Shih H, Niou CS, Zernow L (1993) Dynamic recrystallization in the shaped charge regime. Scr Metall Mater 29:567-572

4. Sakai T, Belyakov A, Kaibyshev R, Miura H, Jonas JJ (2014) Dynamic and post-dynamic recrystallization under hot, cold and severe plastic deformation conditions. Prog Mater Sci 60(1):130-207

5. Murr L, Niou C, Garcia E (1997) Comparison of jetting-related microstructures associated with hypervelocity impact crater formation in copper targets and copper shaped charges. Mater Sci Eng 222:118-132

6. Elshenawy T, Ming Q (2013) Breakup time of zirconium shaped charge jet. Wiley, New York, pp 703-708

7. Guo W, Li SK, Wang FC, Wang M (2009) Dynamic recrystallization of tungsten in a shaped charge liner. Scr Mater 60(5):329-332

8. Yang F, Li C, Cheng S, Wang L, Tian W (2010) Deformation behavior of explosive detonation in electroformed nickel liner of shaped charge with nano-sized grains. Trans Nonferrous Met Soc China 20(8):1397-1402

9. Murr LE, Shih HK, Niou CS (1994) Dynamic recrystallization in detonating tantalum shaped charges: a mechanism for extreme plastic deformation. Mater Charact 33(1):65-74

10. Guo W, Li SK, Wang FC, Wang M (2009) Dynamic recrystallization of tungsten in a shaped charge liner. Scr Mater 60(5):329-332

11. Zernow L, Lowry L (1992) High strain rate deformation of copper in shaped charge jets. In: Meyers MA, Murr LE (eds) Shockwave and high-strain-rate phenomena in materials. Springer, Berlin

12. E 112-96 (2009) Standard test methods for determining average grain size 1. ASTM International, vol. 96, Reapproved 2004

13. Wallis C, Buchmayr B (2019) Effect of heat treatments on microstructure and properties of $\mathrm{CuCrZr}$ produced by laser-powder bed fusion. Mater Sci Eng A 744:215-223
14. Olakanmi E, Cochrane R, Dalgamo K (2015) A review on selective laser sintering/melting (SLS/SLM) of aluminium alloy powders: processing, microstructure and properties. Prog Mater Sci 74:401-477

15. Murr LE, Esquivel EV (2004) Observations of common microstructural issues associated with dynamic deformation phenomena: twins, microbands, grain size effects, shear bands, and dynamic recrystallization. J Mater Sci 39(4):1153-1168

16. Guo W, Li SK, Wang FC, Wang M (2009) Dynamic recrystallization of tungsten in a shaped charge liner. Scr Mater 60(5):329-332

17. Von Holle W, Trimble J (1976) No title. Sixth international symposium on detonation, Colorado, San Diego, pp 691-699

18. Flis WJ (2018) On temperatures in shaped-charge jet penetration

19. Lassila DH, Walters WP, Nikkel DJ, Kershaw RP (1996) Analysis of OSoft "recovered Shaped charge jet particles. This paper was prepared for submittal to the symposium structures under extreme loading conditions at the 1996 American Society of Mechanical Engineers pressure vessels and piping conference

20. Racah E (1988) Shaped charge jet heating. Propellants Explos Pyrotech 13:176-182

21. Agu HO, Hameed A, Appleby-Thomas GJ (2018) Application of shell jetting analysis to determine the location of the virtual origin in shaped charges. Int J Impact Eng 122:175-181

22. Malcolm C (1997) "AUTODYN ${ }^{\circledR}$ jetting tutorial, 3rd revision. Century Dynamics, USA

23. Elshenawy T, Elbeih A, Klapötke TM (2017) A numerical method for the determination of the virtual origin point of shaped charge jets instead of using flash X-ray radiography. Taylor \& Francis, London, pp 1-14

24. Walters W, Zukas JA (1989) Fundamental of shaped charges. Springer, New York

25. Heuzé O (2012) General form of the Mie-Grüneisen equation of state. Comptes Rendus Mec 340(10):679-687

26. Baoxiang R, Gang T, Peng W, Changxing D, Chunqiao P, Hongbo M (2018) Analysis of the formation mechanism of the slug and jet center hole of axisymmetric shaped charges. Results Phys 9:135-141

27. Zernow L (1997) The density deficit in stretching shaped charge jets. Int J Impact Eng 20:849-859

28. Walters WP, Jonas Z (1989) Fundamentals of shaped charges. Springer, New York

Publisher's Note Springer Nature remains neutral with regard to jurisdictional claims in published maps and institutional affiliations. 